\section{Increased numbers of caveolae in retinal endothelium and pericytes in hypertensive diabetic rats \\ NICOLA HILLMAN ${ }^{1}$, SUSAN COX ${ }^{1}$, ALAN R. NOBLE", \\ PATRICK J. GALLAGHER ${ }^{1}$}

\begin{abstract}
Purpose Long-term clinical studies have now shown that tight control of blood pressure in type 2 diabetes reduces the risk of diabetesrelated death and common diabetic complications, including diabetic retinopathy. However, the mechanisms by which hypertension enhances diabetic microvascular disease, especially diabetic retinopathy, are poorly understood. We developed an experimental model of hypertension in diabetic rats and studied the early ultrastructural changes in retinal capillaries under these conditions.

Methods Hypertension was induced in diabetic BioBreeding (BB) rats by unilateral nephrectomy, weekly subcutaneous mineralocorticoid and $0.9 \%$ oral saline. Serial blood pressures and ultrastructural features of retinal capillaries were recorded in four groups: normotensive Wistar rats, normotensive diabetic rats, hypertensive Wistar rats and hypertensive diabetic rats. Results A significant and sustained increase in systolic blood pressure occurred in both groups of nephrectomised rats. There was a significant increase in the number of caveolae (i) in both pericytes and endothelial cells in animals with hypertension and diabetes together compared with all other groups and (ii) in pericytes in animals with diabetes alone. The number of direct contacts between pericytes and endothelial cells was reduced in diabetic and hypertensive diabetic animals. Hypertension and diabetes had an interactive effect in producing retinal capillary basement membrane thickening.

Conclusions In the BB rat hypertension and diabetes have an interactive effect in increasing the number of caveolae in both endothelial cells and pericytes. We speculate that this may be a reflection of changes in calcium and nitric oxide metabolism in these animals.
\end{abstract}

Key words BioBreeding (BB) rats, Caveolae, Diabetic retinopathy, eNOS, Hypertension
Patients with all forms of diabetes have an increased incidence of systemic hypertension, ${ }^{1}$ and those with hypertension and diabetes have a higher risk of renal impairment than subjects with either condition alone. ${ }^{2}$ There is now conclusive evidence that tight control of blood pressure reduces the risk of death related to diabetes, diabetic complications and progression of diabetic retinopathy in type 2 diabetes. ${ }^{3}$ In the early stages of insulindependent diabetes microvascular pressure and flow are increased. However, the mechanisms by which hypertension enhances diabetic microvascular disease, especially diabetic retinopathy, are poorly understood. ${ }^{4,5}$ In a study of spontaneously hypertensive rats made diabetic with streptozotocin, Hammes and colleagues ${ }^{6}$ identified a variety of retinal vascular changes. These included arteriolar microthrombi, microaneurysm formation and vascular deposits of advanced glycation products.

In view of these findings, and because of the current clinical interest in the interaction of diabetes and hypertension, we designed an experiment to study ultrastructural changes in endothelial cells and pericytes in a model of hypertension and diabetes. We found changes in basement membranes and contacts between endothelial cells and pericytes. There were significant, and at present inexplicable, increases in the numbers of caveolae in pericytes and endothelial cells in rats that were both hypertensive and diabetic.

\section{Materials and methods}

Experimental animals

Young spontaneously diabetic BioBreeding (BB) male rats, 60-90 days old (250-300 g), were obtained from a breeding colony at the Biomedical Research Unit, Southampton University Hospitals. Age-matched male Wistar rats were used as controls. Hypertension was induced in groups of both diabetic and control rats using the DOCA salt method. ${ }^{7}$ Under
N. Hillman

S. Cox

P.J. Gallagher

Department of Pathology University of Southampton Southampton, UK

\section{A.R. Noble}

School of Biological Sciences University of Southampton Southampton, UK

Dr Patrick J. Gallagher Department of Pathology MP813

Southampton University Hospital

Southampton SO16 6YD, UK

Tel: +44 (0)2380 796664 Fax: +44 (0)2380 796603 e-mail: pig4@soton.ac.uk

Grant support: British Heart Foundation FS 94083

Received: 19 October 2000 Accepted in revised form: 5 February 2001 
general anaesthesia induced with fentanyl flucanisone and diazepam a left unilateral nephrectomy was performed. Injections of deoxyhydrocorticosterone acetate (DOCA) salt (Sigma), $10 \mathrm{mg}$ weekly (i.m.) were given and drinking water was replaced with $0.9 \%$ saline. We therefore studied four separate groups of animals: normotensive Wistar rats (group 1), hypertensive Wistar rats (group 2), normotensive BB rats (group 3) and hypertensive BB rats (group 4).

These procedures were approved and regulated by the United Kingdom Home Office project licence 90/909. The standard of care of all animals conforms to those of the ARVO Resolution for the Use of Animals in Research.

\section{Periodic observations}

Systolic blood pressure was measured at least once a week by tail artery sphygmomanometry (model 229, Pulse Amplifier System, Life Sciences Instruments, Palo Alto, CA). ${ }^{8}$ Animals were weighed daily and urinary glucose and ketones estimated with BM multistix. Novo Lente porcine insulin (Novo Nordisk, Crawley, W. Sussex, UK) was given at a standard daily dose of 2.4 units for males and 2.0 units for females. This dose was adjusted daily in order to ensure that the animals received the minimum dose consistent with avoiding glycosuria and ketonuria. Human Actrapid insulin (Novo Nordisk) and saline rehydration were used as required.

\section{Preparation of retinal tissues}

After 8 weeks, animals were anaesthetised with sodium pentobarbitone $(60 \mathrm{mg} / \mathrm{kg}$ i.p.) and, following a thoracotomy, perfused via the left ventricle with $3 \%$ glutaraldehyde in cacodylate buffer, $\mathrm{pH}$ 7.4. The eyes were removed intact and fixed in glutaraldehyde for a further $24 \mathrm{~h}$ at $4{ }^{\circ} \mathrm{C}$. Radially orientated sections of the retina, approximately $5 \times 1 \mathrm{~mm}$, were taken from the left eye within $5 \mathrm{~mm}$ of the head of the optic nerve. They were left for at least $12 \mathrm{~h}$ in $0.1 \mathrm{M}$ sodium cacodylate sucrose buffer (pH 7.4) at $4{ }^{\circ} \mathrm{C}$ and then further fixed in $2 \%$ osmium tetroxide for $2 \mathrm{~h}$. The tissue sections were stained in $2 \%$ uranyl acetate for $30 \mathrm{~min}$ and dehydrated through graded ethanol solutions. Sections were then cleared in Histasol (30 min), infiltrated with 50:50 Histasol/Spurr's resin (1 h) and placed in 100\% Spurr's resin $(12 \mathrm{~h})$. Appropriate areas of $1 \mu \mathrm{m}$ sections were selected and cut at $60-90 \mathrm{~nm}$.

\section{Ultrastructural observations}

Membrane-associated vesicles

The numbers of surface-associated vesicles were counted on the luminal and abluminal surfaces of both pericytes and endothelial cells. The area to be studied was defined at low magnification and photographed. Vesicle counts in this area were made directly from the screen at variable magnifications. The total cytoplasmic area was calculated by measuring the area of the pericyte or the endothelial cells and subtracting the area of nucleus included. The results were expressed as the number of vesicles per square micrometre of cytoplasm.

\section{Pericyte-endothelial cell contacts}

Pericyte-endothelial cell contacts were defined as sites where the cell membranes of pericytes and endothelial cells appeared to be in direct contact, with no intervening basement membrane. These included simple apposition contacts, where the cell membranes came together in parallel, or more complex 'peg and socket' patterns involving one or more cellular protrusion. ${ }^{9}$ Counts were made directly from electron micrographs.

\section{Pericyte cover}

The length of the endothelial cell outer membrane in direct apposition to pericyte processes was measured from photomicrographs using a computerised image analysis system (software Colourvision 1.7.4a, Improvision, UK). The results were expressed as a percentage of the total length of the endothelial cell outer membrane.

\section{Basement membranes}

Between 1 and 12 satisfactory capillaries, with sharp basement membrane borders, were present in each grid. Electron photomicrographs were enlarged to $\times 10000$. Basement membrane thickness (BMT) was measured in two different ways. In method 1 a magnifying eyepiece graticule was used to measure 10 random points around the circumference of each vessel, excluding areas where pericytes were present. Method 2 was adapted from that designed by McEwan et al. ${ }^{10}$ Total basement membrane area was measured from each electron micrograph using computerised image analysis. The total length of the lines delimiting the basement membrane (BM) was measured and divided by 2 to give the basement membrane length. Mean BMT was calculated as BM area divided by BM length.

\section{Statistical methods}

Results were analysed by one-way or two-way analysis of variance. A value of $p<0.05$ was defined as significant.

\section{Results}

\section{Periodic observations}

Urinary glucose was less than $28 \mathrm{mmol} / 1$ in all animals throughout the 8 weeks of the study. Ketonuria, which was corrected using Actrapid insulin, was detected on a maximum of 9 days in any one diabetic animal. All DOCA salt nephrectomised animals developed increased blood pressure within 2 weeks. Peak systolic levels were sustained between 4 and 8 weeks. 
Table 1. Summary of results (mean values include standard deviations)

\begin{tabular}{|c|c|c|c|c|}
\hline Measurement & $\begin{array}{l}\text { Control } \\
\text { (group 1) }\end{array}$ & $\begin{array}{l}\text { Hypertensive } \\
\text { (group 2) }\end{array}$ & $\begin{array}{l}\text { Diabetic } \\
\text { (group 3) }\end{array}$ & $\begin{array}{l}\text { Hypertensive diabetic } \\
\text { (group 4) }\end{array}$ \\
\hline \multicolumn{5}{|c|}{ Final systolic blood pressure $(\mathrm{mmHg})$} \\
\hline Mean & $123 \pm 1.9$ & $190 \pm 2.7$ & $124 \pm 3.0$ & $190 \pm 2.2$ \\
\hline No. of eyes (animals) & $6(5)$ & $14(7)$ & $10(5)$ & $8(5)$ \\
\hline No. of capillaries studied & 20 & 21 & 21 & 30 \\
\hline Endothelial cell:pericyte ratio & $1: 2.00$ & $1: 2.03$ & $1: 2.03$ & $1: 2.28$ \\
\hline \multicolumn{5}{|l|}{$\begin{array}{l}\text { Total no. of pericyte vesicles } \\
\text { per } \mu \mathrm{m}^{2} \text { cytoplasm }\end{array}$} \\
\hline Mean & $\begin{array}{l}2.7 \times 10^{-4} \\
\pm 2.4 \times 10^{-4}\end{array}$ & $\begin{aligned} & 4.3 \times 10^{-4} \\
\pm & 2.8 \times 10^{-4}\end{aligned}$ & $\begin{array}{l}6.2 \times 10^{-4} \\
\pm 3.8 \times 10^{-4}\end{array}$ & $\begin{array}{l}10.4 \times 10^{-4} \\
\pm 5.3 \times 10^{-4}\end{array}$ \\
\hline Range & $0.0-11.0 \times 10^{-4}$ & $0.7-10.6 \times 10^{-4}$ & $0.0-14.90 \times 10^{-4}$ & $0.0-20.1 \times 10^{-4}$ \\
\hline \multicolumn{5}{|c|}{$\begin{array}{l}\text { Total no. of endothelial cell vesicles } \\
\text { per } \mu \mathrm{m}^{2} \text { cytoplasm }\end{array}$} \\
\hline Mean & $\begin{array}{l}8.6 \times 10^{-4} \\
\pm 3.5 \times 10^{-4}\end{array}$ & $\begin{array}{l}9.5 \times 10^{-4} \\
\pm 3.2 \times 10^{-4}\end{array}$ & $\begin{array}{l}9.6 \times 10^{-4} \\
\pm 2.2 \times 10^{-4}\end{array}$ & $\begin{array}{l}14.3 \times 10^{-4} \\
\pm 4.4 \times 10^{-4}\end{array}$ \\
\hline Range & $3.3-18.7 \times 10^{-4}$ & $3.6-15.2 \times 10^{-4}$ & $4.3-13.0 \times 10^{-4}$ & $6.7-25.4 \times 10^{-4}$ \\
\hline \multicolumn{5}{|c|}{$\begin{array}{l}\text { No. of pericyte abluminal vesicles } \\
\text { per } \mu \mathrm{m}^{2} \text { cytoplasm }\end{array}$} \\
\hline Mean & $\begin{array}{l}2.3 \times 10^{-4} \\
\pm 2.0 \times 10^{-4}\end{array}$ & $\begin{array}{l}3.9 \times 10^{-4} \\
\pm 2.5 \times 10^{-4}\end{array}$ & $\begin{array}{l}5.8 \times 10^{-4} \\
\pm 3.5 \times 10^{-4}\end{array}$ & $\begin{array}{l}9.3 \times 10^{-4} \\
\pm 4.7 \times 10^{-4}\end{array}$ \\
\hline Range & $0.0-8.6 \times 10^{-4}$ & $0.7-10.1 \times 10^{-4}$ & $0.0-13.3 \times 10^{-4}$ & $0.0-18.8 \times 10^{-4}$ \\
\hline \multicolumn{5}{|c|}{$\begin{array}{l}\text { No. of endothelial cell abluminal } \\
\text { vesicles per } \mu \mathrm{m}^{2} \text { cytoplasm }\end{array}$} \\
\hline Mean & $\begin{array}{l}6.8 \times 10^{-4} \\
\pm 3.0 \times 10^{-4}\end{array}$ & $\begin{array}{l}7.4 \times 10^{-4} \\
\pm 2.5 \times 10^{-4}\end{array}$ & $\begin{array}{l}8.0 \times 10^{-4} \\
\pm 2.1 \times 10^{-4}\end{array}$ & $\begin{array}{l}11.7 \times 10^{-4} \\
\pm 3.9 \times 10^{-4}\end{array}$ \\
\hline Range & $2.9-14.8 \times 10^{-4}$ & $2.9-11.9 \times 10^{-4}$ & $3.9-12.4 \times 10^{-4}$ & $4.5-21.2 \times 10^{-4}$ \\
\hline \multicolumn{5}{|l|}{$\begin{array}{l}\text { No. of pericyte luminal vesicles } \\
\text { per } \mu \mathrm{m}^{2} \text { cytoplasm }\end{array}$} \\
\hline Mean & $\begin{array}{l}0.33 \times 10^{-4} \\
\pm 0.54 \times 10^{-4}\end{array}$ & $\begin{array}{l}0.48 \times 10^{-4} \\
\pm 0.45 \times 10^{-4}\end{array}$ & $\begin{array}{l}0.45 \times 10^{-4} \\
\pm 0.45 \times 10^{-4}\end{array}$ & $\begin{aligned} & 1.2 \times 10^{-4} \\
\pm & 1.1 \times 10^{-4}\end{aligned}$ \\
\hline Range & $0.0-1.99 \times 10^{-4}$ & $0.0-1.99 \times 10^{-4}$ & $0.0-1.66 \times 10^{-4}$ & $0.0-3.6 \times 10^{-4}$ \\
\hline \multicolumn{5}{|l|}{$\begin{array}{l}\text { No. of endothelial cell luminal } \\
\text { vesicles per } \mu \mathrm{m}^{2} \text { cytoplasm }\end{array}$} \\
\hline Mean & $\begin{array}{l}1.8 \times 10^{-4} \\
\pm 0.9 \times 10^{-4}\end{array}$ & $\begin{array}{l}2.0 \times 10^{-4} \\
\pm 1.1 \times 10^{-4}\end{array}$ & $\begin{array}{l}1.6 \times 10^{-4} \\
\pm 0.7 \times 10^{-4}\end{array}$ & $\begin{array}{l}2.6 \times 10^{-4} \\
\pm 0.8 \times 10^{-4}\end{array}$ \\
\hline Range & $0.4-3.9 \times 10^{-4}$ & $0.6-4.7 \times 10^{-4}$ & $0.5-3.1 \times 10^{-4}$ & $1.1-4.2 \times 10^{-4}$ \\
\hline \multicolumn{5}{|l|}{$\begin{array}{l}\text { Pericyte-endothelial cell contacts } \\
\text { per capillary }\end{array}$} \\
\hline Mean & $3.3 \pm 1.3$ & $2.2 \pm 1.5$ & $1.9 \pm 1.1$ & $1.9 \pm 1.4$ \\
\hline Range & $0-5$ & $0-6$ & $0-4$ & $0-5$ \\
\hline Mode & 4 & 2 & 2 & 2 \\
\hline \multicolumn{5}{|l|}{ Percentage pericyte cover } \\
\hline Mean & $59.4 \pm 22.3$ & $64.2 \pm 20.8$ & $46.9 \pm 22.0$ & $54.5 \pm 20.6$ \\
\hline Range & $17.6-99.3$ & $24.7-100.0$ & $5.4-94.1$ & $12.0-86.4$ \\
\hline \multicolumn{5}{|c|}{$\begin{array}{l}\text { Basement membrane thickness (nm): } \\
\text { Method } 1\end{array}$} \\
\hline Mean & $142 \pm 7.8$ & $142 \pm 14.6$ & $144 \pm 31.7$ & $167 \pm 41.6$ \\
\hline Range & 109-168 & $123-169$ & $117-240$ & $126-250$ \\
\hline \multicolumn{5}{|c|}{$\begin{array}{l}\text { Basement membrane thickness (nm): } \\
\text { Method } 2\end{array}$} \\
\hline Mean & $119 \pm 21.5$ & $130 \pm 32.5$ & $112 \pm 27.5$ & $143 \pm 40.6$ \\
\hline Range & 83-178 & $88-220$ & $66-172$ & $98-269$ \\
\hline
\end{tabular}

\section{Plasma-membrane-associated vesicles}

Plasma-membrane-associated vesicles $(60-70 \mathrm{~nm}$ diameter) were identified consistently in both pericytes and endothelial cells (Fig. 1a, b, d). These vesicles were concentrated along the part of the membrane furthest from the capillary lumen. They were not observed as free cytoplasmic vesicles. Detailed results are shown in Table 1. The following comments are made in summary:

\section{Total number of vesicles}

There was a significant increase in the total number of vesicles in both pericytes and endothelial cells in animals with hypertension and diabetes together (group 4) compared with all other groups (pericytes: group 1 , $p<0.01$; group 2, $p<0.01$; group 3, $p=0.03$; endothelial cells: group $1, p=0.01$; group $2, p<0.01$; group 3 , $p<0.01)$. These results suggest that the effect on the increase in the total number of vesicles with 

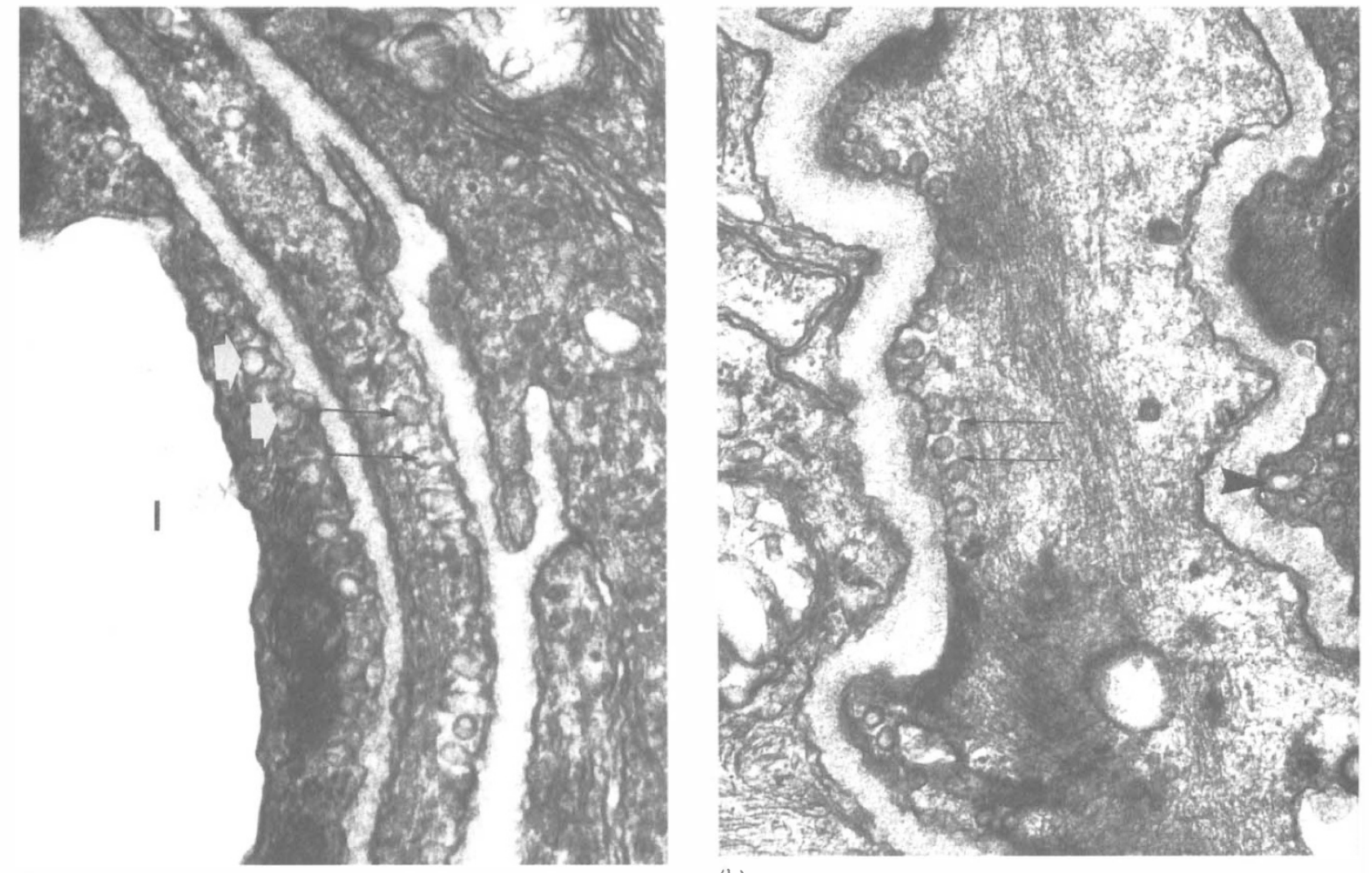

(a)

(b)
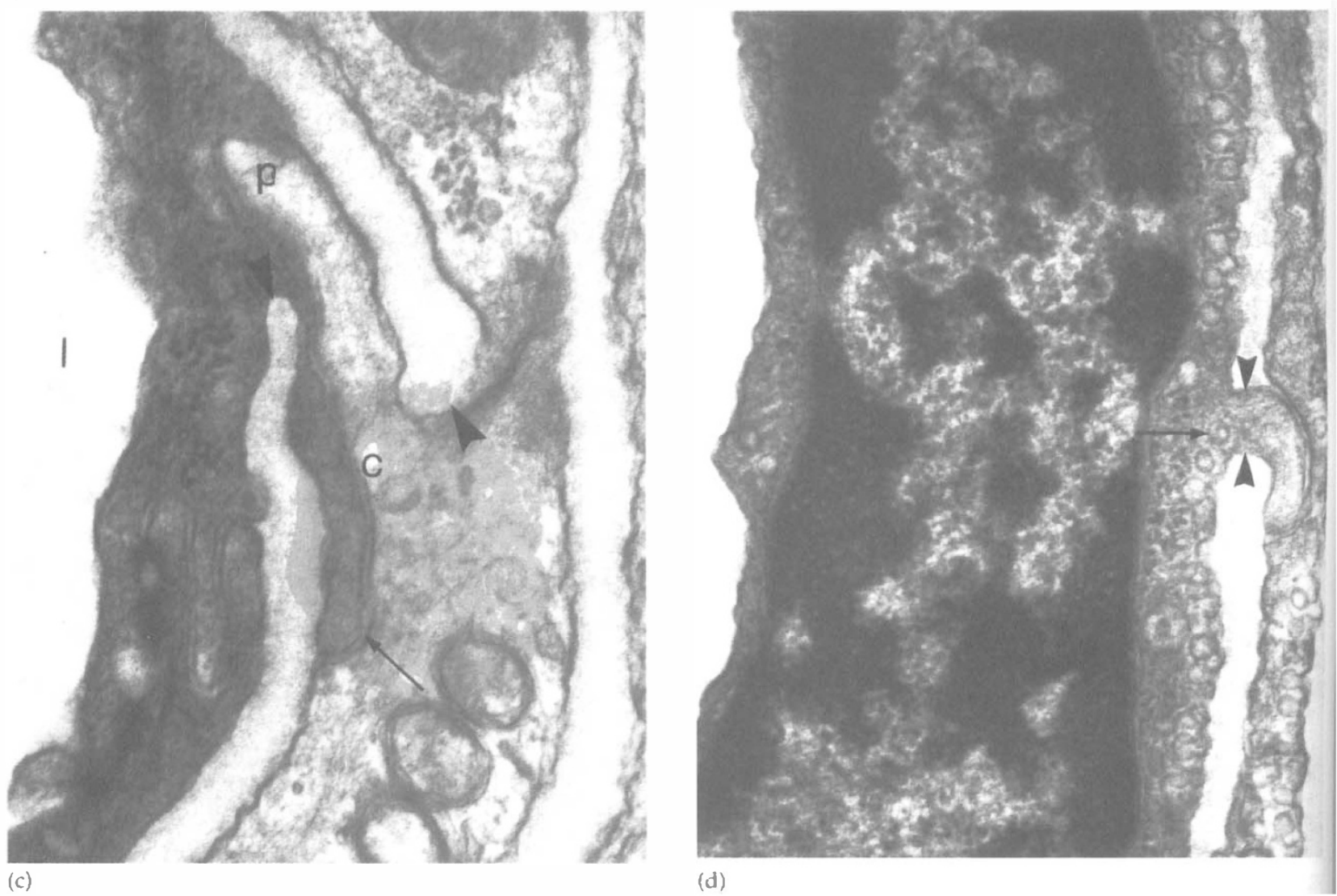

(d)

Fig. 1. Electron micrographs of retinal capillary endothelium. (a) Plasma-membrane-associated vesicles (caveolae) in both an endothelial cell (white arrowheads) and a pericyte (black arrows). Note that caveolae are concentrated at the abluminal surface of each cell type. Normotensive Wistar rat, $\times 40$ 000. (b) Caveolae arranged at the abluminal surface of a pericyte (arrows). Note the prominent microfilaments within the cytoplasm of the pericyte. Some caveolae are visible in the cytoplasm of the adjacent endothelial cell at the left (arrowhead). Hypertensive Wistar rat, $\times 30$ 000. (c) Direct contact between an endothelial cell and a pericyte. Processes from both a pericyte ( $p$ ) and an enidothelial cell (arrow) protrude through a gap in the basement membrane, marked by arrowheads, and are in contact with each other (c). The capillary lumen is to the left (l). Normotensive Wistar rat, $\times 40$ 000. (d) Projection of endothelial cell cytoplasm through a gap in the basement membrane (arrowheads), forming a so-called peg and socket connection with a pericyte. Note the prominent caveolae at the abluminal aspect of the endothelial cell (arrows). Hypertensive diabetic rat, $\times 30000$. 
hypertension and diabetes together, in both pericytes and endothelial cells, was synergistic. In rats with diabetes alone there was a significant increase in the number of vesicles in pericytes $(p=0.04)$ but not endothelial cells. There was no significant effect of hypertension alone in either cell type (pericytes: $p=0.22$; endothelial cells: $p=0.47$ ).

\section{Number of abluminal vesicles}

There was a significant increase in the number of abluminal vesicles in both pericytes and endothelial cells in rats with hypertension and diabetes together, compared with all other groups (pericytes: group 1, $p<0.01$; group 2, $p<0.01$; group 3, $p=0.04$; endothelial cells; group 1, $p=0.01$; group 2, $p<0.01$; group 3, $p<0.01)$. In rats with diabetes alone there was a significant increase in the number of abluminal vesicles in pericytes $(p=0.03)$ but not endothelial cells $(p<0.08)$. There was no effect of hypertension alone in either cell type (pericytes: $p=0.21$, endothelial cells: $p=0.50$ ).

\section{Number of luminal vesicles}

In endothelial cells there was a significant increase in the number of luminal vesicles in rats with hypertension and diabetes together compared with controls $(p=0.02)$ and rats with diabetes alone $(p=0.04)$ but not compared with rats with hypertension alone $(p=0.12)$. In pericytes there was a significant increase in the number of luminal vesicles in rats with hypertension and diabetes together (group 4) compared with all other groups (group 1, $p=0.02$; group 2, $p=0.02$; group $3, p<0.01$ ). There was no significant increase in the number of luminal vesicles in either pericytes or endothelial cells in rats with hypertension alone or diabetes alone.

\section{Other ultrastructural changes}

Direct contacts between pericytes and endothelial cells were identified in the majority of capillaries examined. These included direct appositions between processes which appeared to run parallel to each other and socalled peg and socket contacts ${ }^{9}$ (Fig. 1c, d). These contacts were closely related to defects or gaps in the basement membrane. No junctional complexes were observed at the magnifications that we used in this study. The number of contacts was significantly greater in normotensive Wistar animals (group 1) than in either of the diabetic groups (group 3, $p<0.01$; group 4, $p<0.02)$. There was no significant difference in the number of contacts between hypertensive Wistar animals (group 2) and either of the diabetic groups (group 3, $p=$ 0.83 ; group $4, p=0.67$ ), nor were there significant differences between normotensive diabetic and hypertensive diabetic animals $(p=0.77)$. There were no significant inter-group differences in the percentage of the capillary circumference covered by pericytic processes.
Diabetic animals with hypertension (group 4) showed significant basement membrane thickening compared with the other three groups of animals (Table 1). Using method 1 (see Materials and methods) there was a significant increase in basement membrane thickening in rats with hypertension and diabetes compared with controls $(p=0.04)$. There was no significant increase in rats with hypertension alone $(p=0.27)$ or diabetes alone $(p=0.31)$ compared with controls. Using method 2 (see Materials and methods) there was a significant increase in basement membrane thickening in rats with hypertension and diabetes together compared with rats with diabetes alone $(p<0.05)$ and compared with controls $(p=0.04)$, but not compared with rats with hypertension alone $(p=0.43)$. With both methods it appeared that the increase in basement membrane thickening in hypertensive diabetic animals (group 4) was greater than the added individual effect in animals with hypertension or diabetes alone (groups 2 and 3).

\section{Discussion}

This experimental study in rats has demonstrated that hypertension and diabetes have an interactive effect in producing an increase in the number of membraneassociated vesicles in endothelial cells and pericytes. The size, location and ultrastructural appearances of the vesicles seen suggested that they were caveolae, nonclathrin-coated invaginations of the plasma membrane. ${ }^{11,12}$ The number of direct contacts between pericytes and endothelial cells was reduced in diabetic and diabetic-hypertensive animals. Hypertension and diabetes had an interactive effect on basement membrane thickening.

\section{Physiological role of caveolae}

The biological functions of caveolae are the subject of much current research. They were first implicated in transcytosis of macromolecules, such as low-density lipoprotein. It is now clear that they have a major role in importing and concentrating molecules (potocytosis) and delivering them to specific locations within the cell. ${ }^{12}$ Caveolin, a $22 \mathrm{kDa}$ membrane protein, is an important structural component of caveolae. More than 60 molecules have been identified biochemically or morphologically in caveolae or caveolin-rich membrane domains. These molecules include insulin receptors, the receptor for advanced glycosylation end-products (RAGE) and endothelial nitric oxide synthase (eNOS). ${ }^{11-14}$ In particular caveolae are rich in molecules involved in cell signalling, such as G-protein-coupled receptors, plasma membrane $\mathrm{Ca}^{2+}$ and protein kinase $\mathrm{C}$ (PKC). ${ }^{12}$

Although we cannot explain the increase in caveolae that we demonstrated in hypertensive diabetic animals it is possible that it is related to abnormalities in calcium metabolism. Young spontaneously hypertensive rats show an increase in the number of caveolae in capillary endothelial cells of the myocardium and some of these 
caveolae are aggregated in abnormal clusters. ${ }^{15}$ Endothelial and smooth muscle cell caveolae are thought to be the regulators of cytoplasmic free calcium, containing a pump to remove $\mathrm{Ca}^{2+}$ from the cell, and inositol triphosphate receptors which are thought to facilitate cellular influx of $\mathrm{Ca}^{2+} \cdot{ }^{12,16}$ In healthy cells fluctuations in $\mathrm{Ca}^{2+}$ levels are normalised by activation of PKC. The beta and delta isoforms of PKC are preferentially activated in the vasculature of diabetic animals and this is associated with a variety of pathophysiological changes, including vasoconstriction. ${ }^{17}$ In the context of the current experiments, what evidence there is suggests that a potent activator of PKC, phorbol-12-myristate-13-acetate (PMA), inhibits potocytosis and reduces the number of caveolae in mouse fibroblast and monkey kidney cell cultures. ${ }^{18}$

Capillary perfusion pressure is increased in both systemic hypertension ${ }^{19}$ and diabetes ${ }^{5}$ and the associated increase in haemodynamic shear stress is likely to produce an increase in intracellular $\mathrm{Ca}^{2+} \cdot 20$

Abnormalities in nitric oxide metabolism may also be important in our experimental model as NO synthase has been localised to caveolae ${ }^{21}$ and is acutely stimulated by increases in endothelial intracellular $\mathrm{Ca}^{2+} .22$ In recent experiments using cultured bovine retinal microvascular endothelial cells vascular endothelial growth factor (VEGF) was shown to increase vascular permeability by an eNOS-dependent mechanism of transcytosis in caveolae. $^{23}$

\section{Previous studies of retinal microvasculature}

There are no other comparable reports of retinal pathology in BB rats. Caldwell and Slapnick ${ }^{24}$ studied the retinal microvasculature using freeze-fracture techniques in normal and streptozotocin-treated (insulindependent diabetic) rats. They found, as we did, that plasmalemmal vesicles at the abluminal aspect of pericytes were increased in diabetic animals in comparison with controls. Their studies did not include hypertensive animals. Hammes and colleagues ${ }^{6}$ studied spontaneously hypertensive rats (SHR) made diabetic by intravenous injection of streptozotocin. In comparison with normotensive controls these animals had significantly increased numbers of thrombi and microaneurysms in retinal capillaries and reduced numbers of pericytes. Other investigators have studied direct contacts between endothelial cells and pericytes in animals in the retina, optic nerve, myocardium and granulation tissue, ${ }^{25-27}$ and in skin biopsies from human subjects with insulin-dependent diabetes. ${ }^{28}$ Some of these contacts have been identified as tight junctions, ${ }^{29}$ and, although there is limited understanding of their functions, there is evidence that they may act as a pathway for the transport of epidermal growth factor. ${ }^{27}$ Robison and his colleagues ${ }^{26}$ produced hyperglycaemia in rats by feeding galactose and noted, as we did, a marked reduction in endothelial cell-pericyte contacts in animals with basement membrane thickening.
In conclusion, our experiments have shown that in the $\mathrm{BB}$ rat hypertension and diabetes have an interactive effect in increasing the number of caveolae in both endothelial cells and pericytes. This may be a response to altered intracellular calcium kinetics. The functional significance of this change could be of considerable interest.

We thank the staff of the Biomedical Research Facility for their care of the experimental animals in this study and Drs Kristina Birch and Julie Searle for their help in the early part of this project. The work was supported by the British Heart Foundation.

\section{References}

1. Sowers JR, Epstein M. Risk factors for arterial disease in diabetes: hypertension. In: Tooke JE, editor. Diabetic angiography. London: Edward Arnold, 1999:45-63.

2. Anderson J, Rocchini AP. Hypertension in individuals with insulin dependent diabetes mellitus. Pediatr Clin North Am 1993;40:93-104.

3. UK Prospective Diabetes Study Group. Tight blood pressure control and risk of macrovascular and microvascular complications in type 2 diabetes: UKPDS 38. BMJ 1998:31:703-13.

4. Kohner EM, Patel V, Rassam SMB. Role of blood flow and impaired autoregulation in the pathogenesis of diabetic retinopathy. Diabetes 1995;44:603-7.

5. Tooke JE. Microvascular function in human diabetes: a physiological perspective. Diabetes 1995;44:721-6.

6. Hammes H-P, Brownlee M, Edelstein D, Saleck M, Martin S, Federlin K. Aminoguanidine inhibits the development of accelerated diabetic retinopathy in the spontaneously hypertensive rat. Diabetologia 1994;37:32-5.

7. Mozaffari MS, Jirakulsomchok S, Wyss LM. Effects of simultaneous diabetes and hypertension in an insulin dependent diabetic model. Int J Exp Pathol 1991;72:655-64.

8. Bunag RD, Butterfield J. Tail-cuff blood pressure measurement without external preheating in awake rats. Hypertension 1982;4:898-903.

9. Carlson EC. Fenestrated subendothelial basement membranes in human retinal capillaries. Invest Ophthalmol Vis Sci 1989;30:1923-32.

10. McEwan TAJ, Chakrabarti S, Sima AAF. A rapid reproducible method for determination of basement membrane thickness in biological structures. Comput Biol Med 1987;17:193-7.

11. Lisanti MP, Scherer PE, Vidugiriene J, Tang ZV, Hermanowski Vosatka A, Tu YH, et al. Characterization of caveolin rich membrane domains isolated from an endothelium-rich source: implications for human disease. J Cell Biol 1994;126:111-26.

12. Anderson RGW. Caveolae: the caveolae membrane system. Annu Rev Biochem 1998;67:199-225.

13. Chun M, Liyanage UK, Lisanti MP, Lodish HF. Signal transduction of a $\mathrm{G}$ protein-coupled receptor in caveolae: $\mathrm{co}-$ localisation of endothelin and its receptor with caveolin. Proc Natl Acad Sci USA 1994;91:11728-32.

14. Mastick CC, Brady MJ, Saltiel AR. Insulin stimulates the tyrosine phosphorylation of caveolin. J Cell Biol 1995;129:1523-31.

15. Goto L, Yoshikane H, Honda M, Morioka S, Yamori Y, Moriyama K. Three dimensional observation on sarcoplasmic reticulum and caveolae in mycocardium of spontaneously hypertensive rats. J Submicrosc Cytol Pathol 1992;22:535-42.

16. Fujimoto T. Calcium pump of the plasma membrane is localised in caveolae. J Cell Biol 1993;120:1147-57. 
17. Koya D, King GL. Protein kinase C activation and the development of diabetic complications. Diabetes 1998;47:859-66.

18. Smart EJ, Foster DC, Ying Y-S, Kamen BA, Anderson RGW. Protein kinase $C$ activators inhibit receptor-mediated potocytosis by preventing internalisation of caveolae. J Cell Biol 1994;124:307-13.

19. Williams SA, Boolell M, MacGregor GA, Smaje LH, Wasserman SM, Tooke JE. Capillary pressure and abnormal pressure dynamics in patients with essential hypertension. Clin Sci 1990;79:5-8.

20. Schwarz G, Callewaert G, Droogmans G, Nilius B. Shear stress-induced calcium transients in endothelial cells from human umbilical cord veins. J Physiol (Lond) 1992;458:527-38.

21. Shaul PW, Smart EJ, Robinson LJ, German Z, Yuhanna IS, Ying $Y$, et al. Acylation targets endothelial nitric oxide synthase to plasmalemmal caveolae. J Biol Chem 1996;271:6518-22.

22. Fleming I, Busse R. NO: the primary EDRF. Cell Mol Cardiol 1999;31:5-14
23. Feng YY, Venema VJ, Venema RC, Tsai N, Behzadian MA, Caldwell RB. VEGF-induced permeability increase is mediated by caveolae. Invest Ophthalmol Vis Sci 1999;40:157-67.

24. Caldwell RB, Slapnick SM. Freeze fracture and lanthanum studies of the retinal microvasculature in diabetic rats. Invest Ophthalmol Vis Sci 1992;33:1610-9.

25. Schulze C, Firth JA. Junctions between pericytes and the endothelium in rat myocardial capillaries: a morphometric and immunogold study. Cell Tissue Res 1993;271:145-54.

26. Robison WG, Nagata M, Tillis TN, Laver N, Kinoshita JH. Aldose reductase and pericyte-endothelial cell contacts in retina and optic nerve. Invest Ophthalmol Vis Sci 1989;30:2293-9.

27. Wakui S. Epidermal growth factor receptor at endothelial cell and pericyte interdigitation in human granulation tissue. Microvasc Res 1992;44:255-62.

28. Braverman IM, Sibley J, Keh A. Ultrastructural analysis of the endothelial-pericyte relationship in diabetic cutaneous vessels. J Invest Dermatol 1990;95:147-53.

29. Fujimoto K. Pericyte-endothelial gap junctions in developing rat cerebral capillaries: a fine structural study. Anat Rec 1995;242:562-5. 